Cahiers $d u$ MONDE RUSSE

\section{Cahiers du monde russe}

Russie - Empire russe - Union soviétique et États indépendants

\title{
Jean-Pierre Bertin-Maghit, éd., Une histoire mondiale des cinémas de propagande
}

\section{Cloé Drieu}

\section{OpenEdition}

\section{Journals}

Édition électronique

URL : https://journals.openedition.org/monderusse/7024

DOI : 10.4000/monderusse. 7024

ISSN : $1777-5388$

Éditeur

Éditions de l'EHESS

\section{Édition imprimée}

Date de publication : 28 décembre 2008

Pagination : 848-851

ISBN : 978-2-7132-2197-2

ISSN : $1252-6576$

Référence électronique

Cloé Drieu, « Jean-Pierre Bertin-Maghit, éd., Une histoire mondiale des cinémas de propagande », Cahiers du monde russe [En ligne], 49/4 | 2008, mis en ligne le 24 décembre 2009, consulté le 04 septembre 2022. URL : http://journals.openedition.org/monderusse/7024 ; DOI : https://doi.org/ 10.4000 /monderusse.7024

Ce document a été généré automatiquement le 4 septembre 2022.

Tous droits réservés 


\title{
Jean-Pierre Bertin-Maghit, éd., Une histoire mondiale des cinémas de propagande
}

\author{
Cloé Drieu
}

\section{RÉFÉRENCE}

Jean-Pierre Bertin-Maghit, éd., Une histoire mondiale des cinémas de propagande.

Monts : Nouveau Monde Éditions, 2008, 816 p. (supplément DVD - 4 h d'archives).

1 Ce livre, qui repose sur une approche comparatiste et fait appel à de nombreuses contributions internationales, est une véritable somme sur les cinémas de propagande politique. Plus d'une trentaine d'auteurs sont réunis sous la direction de Jean-Pierre Berthin-Maghit - historien spécialiste du cinéma français sous l'occupation ${ }^{1}$, qui n'a malheureusement rédigé que l'introduction de l'ouvrage - pour traiter d'une période allant de 1898, avec les premiers usages politiques du film dans le conflit hispanoaméricain, jusqu'au milieu des années 1960, époque marquée par l'essor de la télévision. Les auteurs se penchent sur les films de fiction, les documentaires et les actualités produits par les studios des plus grandes puissances mondiales : États-Unis, URSS, Europe (France, Espagne, Italie, Angleterre, Allemagne, Suisse) et Japon dans une très large mesure, ainsi que l'Amérique Latine (Cuba, Brésil) et la Chine. On pourra regretter que d'autres pays communistes n'y figurent pas, comme ceux d'Europe centrale et orientale par exemple.

2 Cet ouvrage collectif est divisé en quatre parties organisées chronologiquement et de longueur équivalente, à l'exception du premier chapitre, assez court (moins d'une vingtaine de pages), intitulé " De l'origine de la propagande filmée », et qui se focalise sur les premiers usages du film à des fins patriotiques: le conflit hispano-américain (Cuba, 1898) et la Première Guerre mondiale. On y apprend grâce à Emmanuel Vincenot, non sans une certaine jubilation, que la guerre qui opposait les États-Unis à l'Espagne - 
notamment la bataille navale durant laquelle les navires américains réussirent à couler la flotte espagnole - n'a pu être filmée en temps réel. La bataille a fait l'objet d'une reconstitution grâce à une bassine remplie d'eau et de quelques maquettes de navire (les objectifs étant de mauvaise qualité, le rendu paraissait des plus réalistes pour le public de l'époque). Cette étude des premiers "films de guerre" se poursuit avec celle du premier conflit mondial, plus longuement et richement traité par Laurent Véray, dans une approche comparatiste (France, Allemagne, Royaume-Uni). L'auteur s'attache à donner un vaste panorama très dense de ce que représente et révèle le film dans l'effort de guerre, y compris la manière dont il se met à son service (film sur le recrutement des soldats, invitation des vedettes de cinéma sur le front, représentation cinématographique des femmes, vulgarisation scientifique), jusqu'à une analyse des films de fiction. Le cinéma semble investir à tout point de vue l'« espace de guerre ", mais le paradoxe réside finalement dans sa défaillance à rendre l'extrême violence des affrontements (p. 45).

Les chapitres II et III sont consacrés au cinéma produit dans l'entre-deux-guerres et durant la Seconde Guerre mondiale. Plusieurs articles sont axés sur la thématique " cinéma et totalitarisme " (Allemagne nazie et Union soviétique). La notion de « film totalitaire » est largement utilisée et détaillée dans un article de Jérôme Bimbenet sur le cinéma dans l'Allemagne nazie, où l'auteur retrace le parcours de Leni Riefenstahl et décrit l'imaginaire nazi, dans lequel eschatologie et messianisme constituent des points de convergence avec l'idéologie soviétique. En se focalisant sur la période 1924-1928, François Albéra invite le lecteur à s'interroger sur la distinction entre "propagande ", « agitation » et « endoctrinement » (en référence à Hannah Arendt), ainsi qu’à replacer la propagande cinématographique dans un environnement visuel large (tracts, banderoles, etc.). Oksana Bulgakowa analyse la période suivante et revient sur une histoire institutionnelle - prise de contrôle progressive du parti dans l'industrie cinématographique, en insistant sur la place de Staline - qu'elle met en regard avec une étude plus ou moins développée de nombreux films de fiction. Si les deux contributions précédentes participent d'une synthèse ou d'un approfondissement de notre connaissance du cinéma soviétique à cette période, l'article de Valérie Pozner, en étudiant les actualités soviétiques de la Seconde Guerre mondiale et le travail des opérateurs envoyés au front, éclaire un champ quasiment neuf au plan historiographique ${ }^{2}$, grâce notamment à un recours aux documents d'archives: RGALI, RGASPI, fonds du Musée du Cinéma (Moscou), RGAKFD ou de sources primaires éditées ${ }^{3}$. En soulignant l'hétérogénéité des images, la difficulté de l'organisation (et des tutelles de référence), la place et le rôle des instances militaires, et plus largement le rapport au "réel de guerre » des opérateurs qui font l'expérience d'une autonomie nouvelle, cette contribution permet de fissurer davantage l'impression d'une machine de propagande soviétique bien rodée. Si elle pouvait être considérée comme telle juste avant le déclenchement de la guerre, la délocalisation des studios qui s'ensuit et la nécessité d'éveiller des sentiments patriotiques soviétiques - propagande d'un ordre nouveau constituent un nouvel enjeu, tant pour le pouvoir que pour les opérateurs eux-mêmes. Cela leur impose de s'interroger à nouveau sur le rapport au réel et la place de la reconstitution ou de la mise en scène dans la traduction de celui-ci.

Si les articles s'intéressent, pour une large part, à la soumission institutionnelle de l'industrie du film au pouvoir politique - et implicitement au rôle des régimes autoritaires dans la genèse d'une industrie cinématographique puissante --, le livre aborde également les initiatives "d'en bas» dans l'effort de propagande ainsi que 
l'importance du film comme instrument de la diplomatie. En prenant le cas des studios hollywoodiens par exemple, la propagande est évoquée par les aspects à la fois commerciaux et populaires du soutien patriotique à l'effort de guerre. La question du film comme " arme de diplomatie internationale ", avec ses limites, ou celle du rôle des ambassades dans l'interdiction d'un film, sont également posées dans le cas du Troisième Reich. L'étude du Japon, par le biais de deux articles de Mathieu Capel, offre un décentrement du regard intéressant en évoquant la politisation des arts - accessoirement sa "bolchévisation»- et, en particulier, le travail de la Ligue japonaise du cinéma prolétarien (Prokino). Ses principaux membres intègrent les grands studios de cinéma suite à la Loi de 1939 qui régit l'ensemble des activités cinématographiques - pour les besoins de la guerre (le cinéma avait déjà reflété dès 1905 le conflit russo-japonais). Enfin est posée à plusieurs reprises la question des liens entre propagande, patriotisme et nationalisme.

5 Il est bien sûr difficile de retranscrire précisément l'ensemble des problématiques abordées dans cet ouvrage ou d'en faire une synthèse, tant les approches, ou les regards historiographiques et géographiques, diffèrent. C'est bien sûr la typologie extrêmement variée des situations qui constitue l'un des points forts de l'ouvrage et qui permet de dessiner de grandes bornes chronologiques, le début des années 1930 constituant globalement un tournant important, quelle que soit la région du monde considérée, avec une politisation de plus en plus marquée de la production cinématographique. De plus, certains articles - peut-être trop rares - offrent des contrepoints pertinents parce qu'ils saisissent les limites de la propagande politique par le biais du cinéma en traitant d'autres moyens d'information ou d'influence sur les masses. C'est le cas de l'article de Sylvie Lindeperg, "Spectacles du pouvoir gaullien: le rendez-vous manqué des actualités filmées ». En rappelant que les prises de vues d'actualités montrant le général de Gaulle sont diffusées avec un certain retard et en étudiant les décalages entre l'événement et sa restitution visuelle, l'auteur insiste sur la primauté des transmissions radiophoniques des discours, parce qu'elles "portent les messages dans l'instant" (p. 498). Après la guerre, la télévision deviendra un outil privilégié de la propagande d'État - avec un contrôle absolu de l'information filmée - et un genre nouveau inventé par le fondateur de la $\mathrm{V}^{\mathrm{e}}$ République: les allocutions en direct. Le Général s'invite désormais dans l'intimité des foyers pour s'adresser directement à chaque téléspectateur. À titre de comparaison, et pour cerner davantage la force et les limites de la " cinécratie » - les termes de " radiocratie » et " télécratie » sont évoqués par l'auteur en référence à l'ouvrage de Georges Balandier ${ }^{4}$-, il aurait été intéressant de contextualiser davantage dans l'ouvrage le médium cinématographique en le replaçant dans un ensemble plus large de moyens de communication dont dispose le pouvoir politique pour agir sur les masses. Quels sont par exemple les nouveaux enjeux, les difficultés et objectifs qui se posent au cinéma à partir du moment où le petit écran prend son essor? Néanmoins, ce livre permet d'appréhender, par des cas particuliers, la dimension politique globale du cinéma et les à-coups subis par la propagande qui doit constamment s'adapter aux grandes ruptures de l'histoire (guerres, guerre froide, propagande interne, etc.). 


\section{NOTES}

1. Voir en particulier son ouvrage Le cinéma français sous l'occupation : le monde du cinéma français de 1940 à 1946, P. : Olivier Orban, 1989 (rééd., 2002, P. : Perrin).

2. Voir également: Valérie Pozner, «Les actualités soviétiques de la Seconde Guerre mondiale ", in Natacha Laurent, éd., Le cinéma «stalinien ": questions d'histoire, Toulouse : Presses universitaires du Mirail / La Cinémathèque de Toulouse, 2003, p. 123-141.

3. V. I. Fomin, éd., Kino $i$ voina : documenty $i$ svidetel'stva [Le cinéma et la guerre : documents et témoignages], Moscou : Materik, 2005, 941 p.

4. Le Pouvoir sur scènes, Paris : Balland, 1992. 